\title{
A High Efficiency Surface Modification Process for Multiwalled Carbon Nanotubes by Electron Cyclotron Resonance Plasma
}

\author{
Wen-Shou Tseng, ${ }^{\dagger}$ Chyuan-Yow Tseng, ${ }^{\dagger}$ Pi-Kai Chuang, ${ }^{\dagger}$ An-Ya Lo, ${ }^{\dagger}$ and Cheng-Tzu Kuo $*, \S$ \\ Department of Materials Science and Engineering, National Chiao Tung University, 1001 University Road, \\ Hsinchu, Taiwan, Department of Vehicle Engineering, National Pingtong University of Science and \\ Technology, 1, Hseuh Fu Road, Neipu Hsiang, Pingtung, Taiwan, and Institute of Materials and Systems \\ Engineering, MingDao University, 369 Wen-Hua Road, Peetow, ChangHua, Taiwan
}

Received: April 1, 2008; Revised Manuscript Received: September 16, 2008

\begin{abstract}
A novel process of surface modification for multiwalled carbon nanotubes (MWCNTs) by using electron cyclotron resonance plasma is proposed. The process uses a $\mathrm{H}_{2} / \mathrm{O}_{2}$ gas mixture as etching gas and applies a bias voltage of $-250 \mathrm{DCV}$ to the process stage to extract and accelerate hydrogen and oxygen cations. The generated high density and high incident energy cations are employed to create defects on the surface of nanotubes through ion bombardment. The oxygen cations with high reduction potential are simultaneously applied, oxidizing the surface of the nanotubes so as to form functional groups on the side walls most effectively. Additionally, being far from the plasma sheath, the MWCNTs can be maintained at a lower temperature to prevent from being decomposed under the high energy plasma. The efficiency of this method was systematically analyzed using X-ray photoelectron spectroscopy, scanning electron microscopy, transmission electron microscopy, Raman spectroscopy, and thermogravimetric analysis. The experimental results have shown that the proposed method is a highly effective way to functionalize MWCNTs, resulting in the nanotubes with high concentration of oxygen-containing functional groups and minimal structural damage within very short process time.
\end{abstract}

\section{Introduction}

Because of their fascinating mechanical and electrical properties, ${ }^{1}$ for the past decade carbon nanotubes (CNTs) have been considered as promising materials for many different applications. ${ }^{2-5}$ One of the key difficulties for application is the required separation of a single tube from agglomerated bundles by dispersing them in an aqueous or polymer matrix. Until recently, most approaches have attempted to functionalize the nanotubes by way of chemical modification, fluorination, and polymer wrapping. ${ }^{6-8}$ The theory behind this is that the formation of polar functional groups on the surface of CNTs enhances their solubility and dispersion abilities in water or polymers. At present, the chemical modification method is the most common; in this process, CNTs are normally refluxed or sonicated in a strong acid, such as $\mathrm{HNO}_{3}$ and/or $\mathrm{H}_{2} \mathrm{SO}_{4}$, to introduce oxygencontaining functional groups, such as $-\mathrm{C}=\mathrm{O},-\mathrm{C}-\mathrm{OH}$, and $-\mathrm{COOH}$, to the surface. However, the harsh conditions inherent in this method may introduce wall damage, decreasing their stability and even cleaving them into shorter pieces. ${ }^{9-11}$ Wet processes may also give rise to some unfavorable issues such as waste treatment, as well as time and cost efficiency issues.

As compared to the chemical modification processes, plasma treatment has gained lots of attention recently because it is a solvent-free, time efficient, versatile, and environmentally friendly procedure for surface modification. ${ }^{12-26}$ In addition, this method can provide the greatest opportunity to scale up the production if the system is optimized. Therefore, plasma treatment has been used for a long time in deposition and etching

* To whom correspondence should be addressed. E-mail: kuoct@ mdu.edu.tw.

$\dagger$ National Chiao Tung University.

¥ National Pingtong University of Science and Technology.

$\S$ MingDao University. processes in many industrial fields. In most cases for surface modification, CNTs are normally treated through exposure to the plasma. The generated ions, radicals, and UV light in plasma interact with the CNT surface, creating active defect sites and bonding functional groups to these sites. ${ }^{18}$ Although plasma treatment has been shown to be effective in facial modification of CNTs, some have mentioned that it may cause serious structural damage due to the high energy and temperature plasma within very short time. ${ }^{18,21}$ An alternative that circumvents these issues is placing the nanotubes away from plasma sheath and extracting plasma ions by applying a bias voltage so as to reduce temperature, radiation, and ion density. However, in most designs, plasma sources are working at around 0.1-1 Torr pressure, which leads to low mean-free-path; this in turn leads to low etching efficiency if the alternative is applied. Active plasma at higher-vacuum pressure may be an optimal solution, but this results in a low density plasma that cannot be activated.

ECR plasma system has been a popular etching method in many applications because, with divergent magnetic flux and high bias voltage, this system can possess excellent features of high ionization efficiency, high density plasma generation in low-pressure vacuum, and effective plasma ion extraction and transportation. ${ }^{27}$ These give the advantages that the positive or negative ions can be easily extracted and transported toward the specimen with high incident energy; the specimen can be placed far from plasma sheath and then treated at relative low temperature. These advantages are very important for conducting a highly efficient etching process and causing no severe structural damage of the specimen. On the basis of this idea, we propose a method to manage the difficulties in plasma treatment of CNTs mentioned above.

The method involves using ECR plasma system and applying an $\mathrm{H}_{2} / \mathrm{O}_{2}$ gas mixture as an etching gas to generate high density 


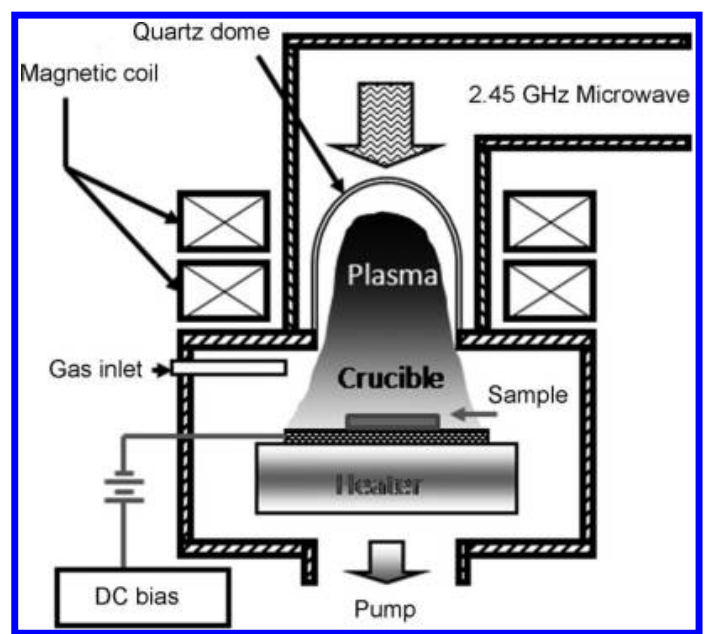

Figure 1. Schematic of the ECR plasma apparatus.

and high incident energy hydrogen and oxygen cation stream to create high density defects on the surface of multiwalled carbon nanotubes (MWCNTs) through highly efficient ion bombardment with minor negative consequences. Because of their high reduction potential, oxygen cations are simultaneously used to oxidize the MWCNT surface so as to form oxygen functional groups with high concentration on the side walls. For comparison, acid treatment using $\mathrm{HNO}_{3} / \mathrm{H}_{2} \mathrm{SO}_{4}$ solution was also conducted for $9 \mathrm{~h}$ to functionalize MWCNTs. The resulting surface structure was analyzed by X-ray photoelectron spectroscopy (XPS). The morphology changes were observed using scanning electron microscopy (SEM) as well as transmission electron microscopy (TEM). In addition, Raman spectroscopy was used to monitor the formation of defects, and thermogravimetric analysis (TGA) was carried out to measure the thermal stability of the MWCNTs.

\section{Experimental Section}

2.1. Plasma Treatment. The ECR plasma apparatus is shown in Figure 1. The MWCNTs, provided by a commercial company, were grown by thermal chemical vapor deposition. As can be seen in Figure 1, $0.05 \mathrm{~g}$ samples of pristine MWCNTs were transported in a crucible and placed on the process stage in the vacuum chamber of the ECR plasma system. To ensure a sufficient density of plasma and an adequate mean free path, chamber pressure was held at $4.2 \times 10^{-3}$ Torr. The output power of the microwave generator was set at about $750 \mathrm{~W}$, and 2.45 $\mathrm{GHz}$ microwaves were introduced into the plasma chamber through a quartz window. The magnetic coil was arranged around the periphery of the chamber, and the magnetic flux
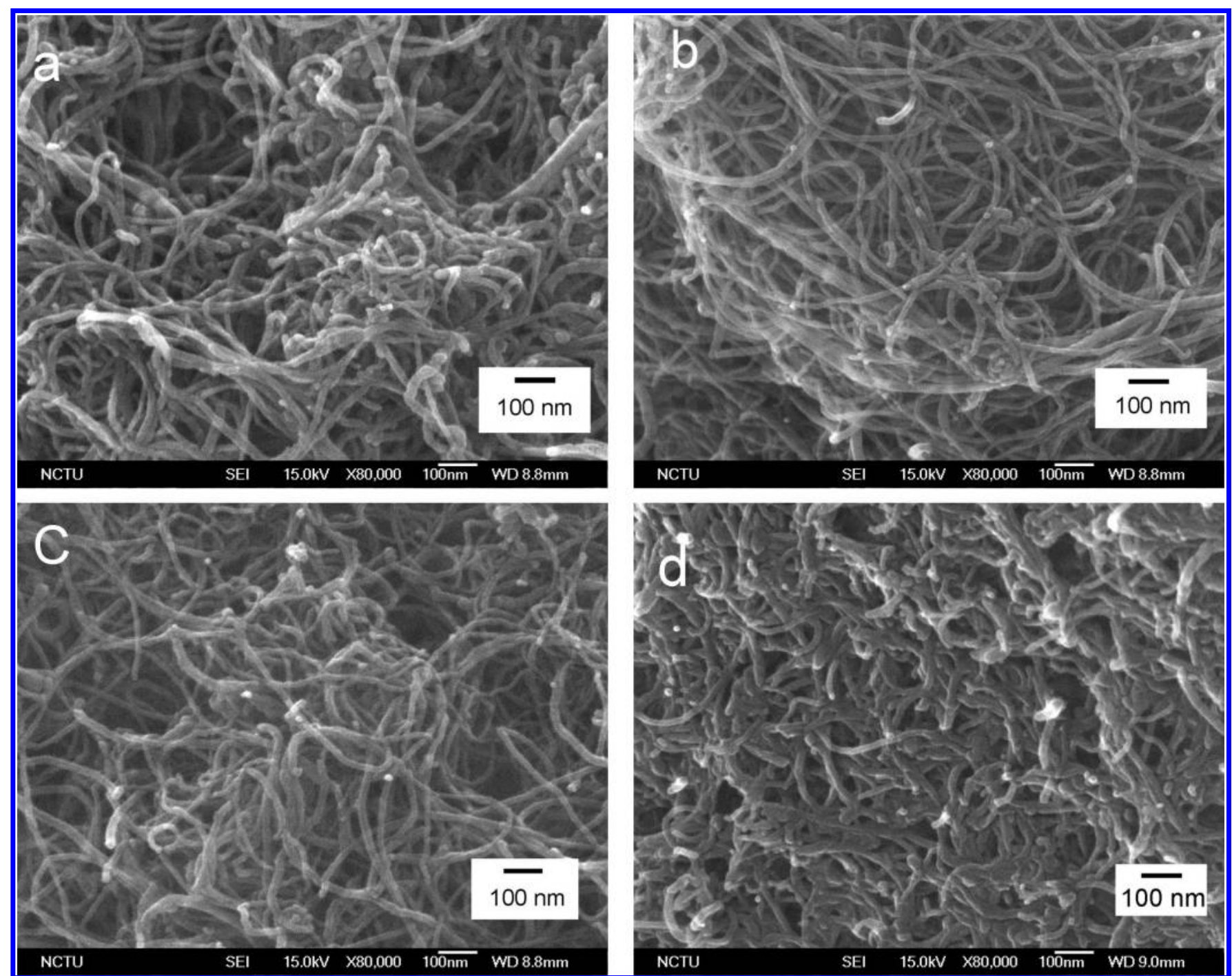

Figure 2. SEM images of (a) the pristine MWCNTs, and the MWCNTs treated by (b) the ECR plasma for 5 min, (c) the ECR plasma for 20 min, and (d) the acid treatment $\left(\mathrm{HNO}_{3}: \mathrm{H}_{2} \mathrm{SO}_{4}=1: 3(\mathrm{v} / \mathrm{v})\right)$ for $9 \mathrm{~h}$. 


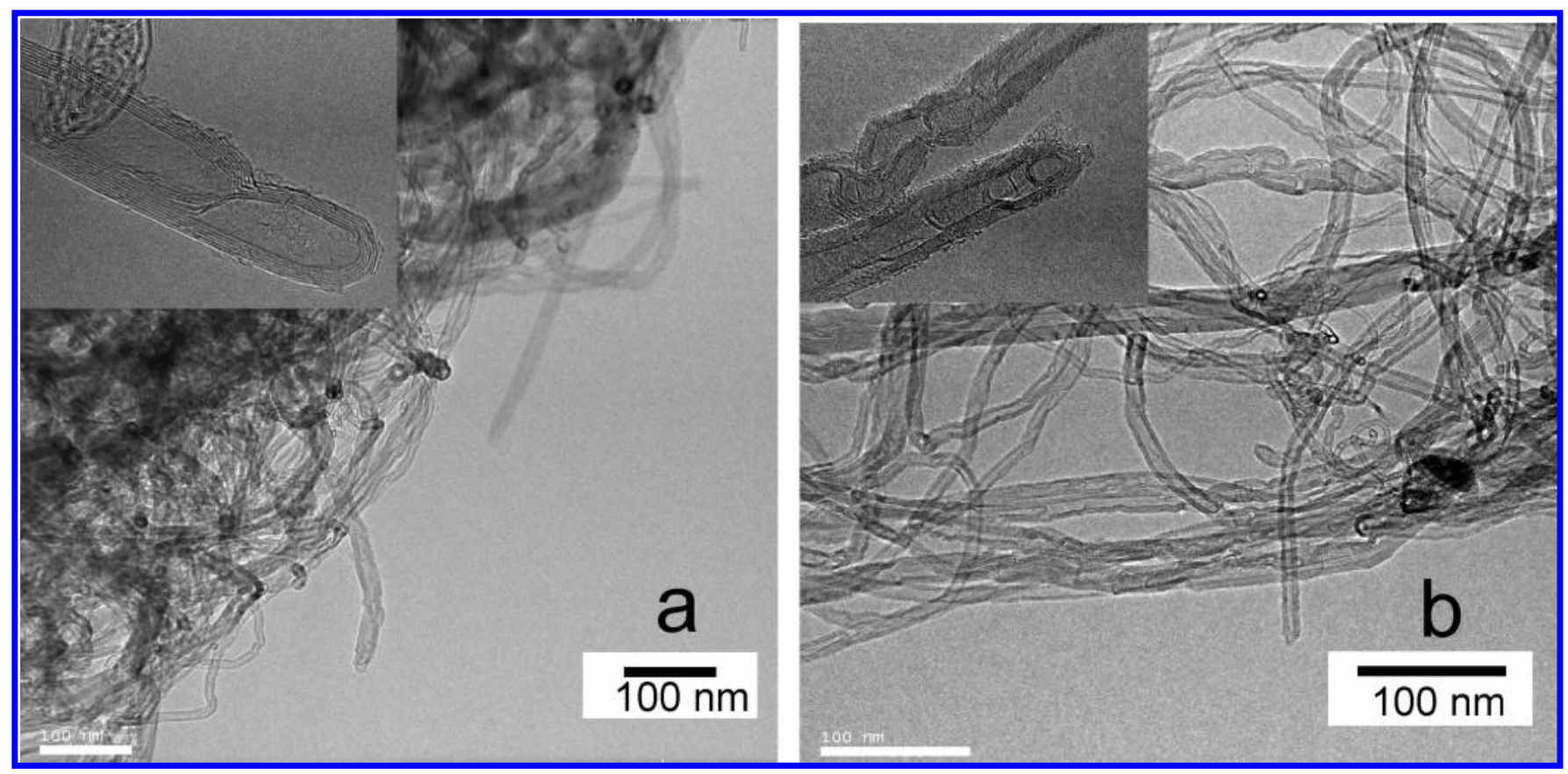

Figure 3. TEM images of (a) the pristine MWCNTs and (b) the MWCNTs treated by the ECR plasma for 5 min.

density was 875 Gauss to meet the ECR condition at the microwave frequency used. A $\mathrm{H}_{2} / \mathrm{O}_{2}$ gas mixture with a flow ratio of $25 / 25(\mathrm{sccm} / \mathrm{sccm})$ was used as an etching gas. A bias voltage of $-250 \mathrm{DCV}$ was applied to the stage to extract and accelerate the hydrogen and oxygen cations in the plasma toward the specimens. Once the stage temperature reached $400{ }^{\circ} \mathrm{C}$, the plasma treatment was conducted for 5 and $20 \mathrm{~min}$.

2.2. Acid Treatment. $0.02 \mathrm{~g}$ of pristine MWCNT powder was immersed in $10 \mathrm{~mL}$ of $\mathrm{HNO}_{3} / \mathrm{H}_{2} \mathrm{SO}_{4}\left(\mathrm{HNO}_{3}: \mathrm{H}_{2} \mathrm{SO}_{4}=1: 3\right.$ (v/v)) solution, and the CNTs/acid mixture was then ultrasonicated for $9 \mathrm{~h}$ at room temperature. Subsequently, the mixture was diluted with deionized water and filtered by using a 0.2 $\mu \mathrm{m}$ porous polytetrafluoroethylene (PTFE) membrane disk to remove the excess acid from the solution. At last, the deposited black powder was washed from the disk filter using ethanol and then dried at $110{ }^{\circ} \mathrm{C}$ on a hotplate for $16 \mathrm{~h}$.

2.3. Material Characterization. To observe the morphology changes, the samples of pristine MWCNTs and the MWCNTs treated by the ECR plasma and acid treatments were measured by using a SEM (JEOL, JSM-6500F). Before the measurement, each sample was sonicated in ethanol for $30 \mathrm{~min}$ and dispersed onto a silicon wafer. Meanwhile, the microstructures of the samples were characterized by TEM (JEOL JEM-2100). The samples were prepared by dispersing and then depositing the black powder on lacy carbon grids by using ethanol.

XPS (Perkin-Elmer model PHI 1600) was performed to determine the chemical changes on the surface of nanotubes. Being a sensitive technique, XPS is used to probe material from the surface down to $5 \mathrm{~nm}$ deep so as to estimate the extent of aromatic group formation on the surface of the nanotubes. Prior to measurement, each specimen was attached to Scotch tape to avoid dispersion of the nanotubes in the vacuum chamber. Monochromated $\mathrm{Al} \mathrm{K} \alpha$ radiation $(h v=1486.6 \mathrm{eV}$ ) was used as the photon source, and photoelectrons were collected at an angle of $54.7^{\circ}$ relative to the normal direction of the specimen surface. The energy resolution of the system was set to $0.2 \mathrm{eV}$. During $C_{1 s}$ spectrum analysis (Spectral Data Processor (SDP) v4.0, XPS international, LLC), background noise was subtracted by using the "Linear" mode in the range between 281.5 and
$293 \mathrm{eV}$, and the component peak fitting was performed by using Gaussian line shapes.

Raman spectroscopy (Jobin YVON LabRam HR800) provided a rapid way to monitor the defect formation of MWCNTs. The exciting source was an Ar laser $(514 \mathrm{~nm}$ ) focused $(50 \times)$ to a $2 \mu \mathrm{m}$ spot size. All spectra were collected with five accumulations of $3 \mathrm{~s}$ each. TGA (TA Q500) was used to characterize the changes in thermal stability with a heating rate of $10^{\circ} \mathrm{C} / \mathrm{min}$ in air flow $(60 \mathrm{~mL} / \mathrm{min})$.

\section{Results and Discussion}

As shown in Figure 2a, the SEM image shows that the pristine MWCNTs are highly tangled with nearly endless tubes and with diameters ranging from 15 to $30 \mathrm{~nm}$. After the ECR plasma treatment for 5 and $20 \mathrm{~min}$, there is no obvious change in morphology (Figure $2 b$ and $c$ ), and this indicates that the ion bombardment of the ECR plasma treatment in this study is moderate. Figure $3 \mathrm{a}$ and $\mathrm{b}$ shows the TEM images of the pristine MWCNTs and the MWCNTs treated by the ECR plasma for 5 min. The microstructures of the samples are observed to have a high density of defects; both are composed of many cylindrical graphite layers. The images confirm that the microstructures and the diameter distribution of the nanotubes are without obvious change after the ECR plasma treatment. By contrast, after the acid treatment for $9 \mathrm{~h}$, the MWCNTs (Figure 2d) are obviously shorter, and the diameter distribution ranges from approximately 25 to $30 \mathrm{~nm}$. This leads to a larger average diameter than that of the pristine MWCNTs. These results match previous studies, which suggest that the harshness of the acid treatment reduces the length, narrows the diameter distribution, and increases the average tube diameter of the CNTs. ${ }^{10,11}$

In Figure 4, the XPS survey spectra reveal the presence of carbon and oxygen on the pristine MWCNTs and the MWCNTs treated by the plasma and acid treatments. The spectra are normalized with respect to $\mathrm{C} 1 \mathrm{~s}$ intensity for comparison purposes. It is observed that, as compared to the pristine MWCNTs, the plasma and acid treated nanotubes have higher concentrations of oxygen on the surface (up to $\sim 50 \%$ ). With reference to previous studies, ${ }^{18,28}$ the $\mathrm{C} 1 \mathrm{~s}$ spectrum (Figure 5) 


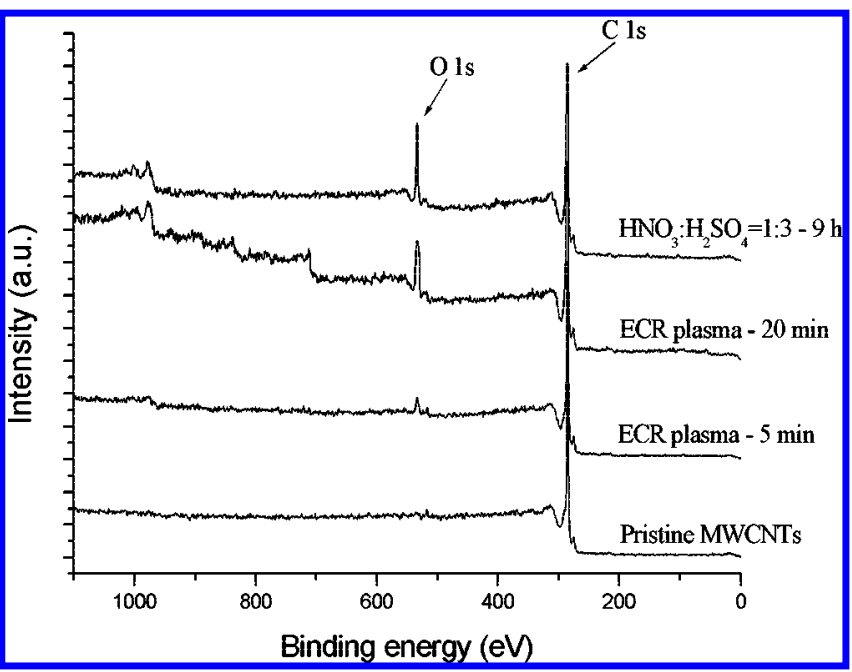

Figure 4. XPS survey spectra of the pristine MWCNTs and the ECR plasma and acid $\left(\mathrm{HNO}_{3}: \mathrm{H}_{2} \mathrm{SO}_{4}=1: 3(\mathrm{v} / \mathrm{v})\right)$ treated MWCNTs.

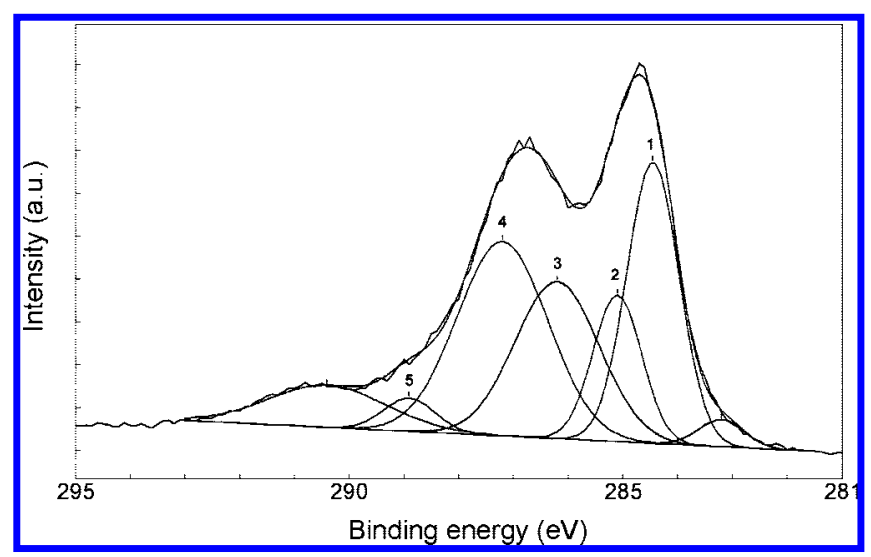

Figure 5. XPS C1s spectrum of the MWCNTs treated by ECR plasma for $20 \mathrm{~min}$. The curve deconvolution suggests the presence of five chemical species: (1) graphite, (2) $\mathrm{sp}^{3}$ carbon, (3) hydroxyl groups, (4) carbonyl groups, and (5) carboxyl groups.

of the MWCNTs treated by the ECR plasma for $20 \mathrm{~min}$ is deconvoluted into five Gaussian peaks centered at $284.5 \pm 0.2$, $285.1 \pm 0.2,286.2 \pm 0.2,287.2 \pm 0.2$, and $288.9 \pm 0.2 \mathrm{eV}$. Here, the main peak at $284.5 \mathrm{eV}$ originates from the graphite signal. The peak at 285.1 is assigned to $\mathrm{sp}^{3}$ carbon atoms. The peaks at 286.2, 287.2, and $288.9 \mathrm{eV}$ correspond to hydroxyl, carbonyl (or ether), and carboxyl (or ester) signals, respectively. With a total intensity of about $4-8 \%$, the peak assigned to $\pi-\pi^{*}$ shakeup bonds is also observed at $290.4 \mathrm{eV} \cdot{ }^{19,29}$ The peak at $283.2 \mathrm{eV}$ is assigned as carbidic carbon. ${ }^{30}$

The C 1s spectra of the four MWCNT samples are shown in Figure 6, and the curve-fitting results are given in Table 1. It is noted that the $[\mathrm{O}] /[\mathrm{C}]$ ratio in the table is based on the relative percentage of three carboxyl groups to all of the carbon atoms detected. ${ }^{21,28}$ Interestingly, as demonstrated in the table, the oxygen functional groups have already been grafted on the MWCNT surface with a concentration of about $11.2 \%$ prior to shipment through acid treatment for purification purpose. When the sample is treated by using the ECR plasma for $5 \mathrm{~min}$, the XPS measurement results show that the concentration of oxygen-containing groups increases from $11.2 \%$ to $31.1 \%$. Meanwhile, the concentration can increase up to $59.8 \%$ when process time increases to $20 \mathrm{~min}$. As compared to the sample treated by the acid treatment, the MWCNTs treated by the ECR plasma for 20 min receive more oxygen-containing functional groups on the surface of the nanotubes. Furthermore, the

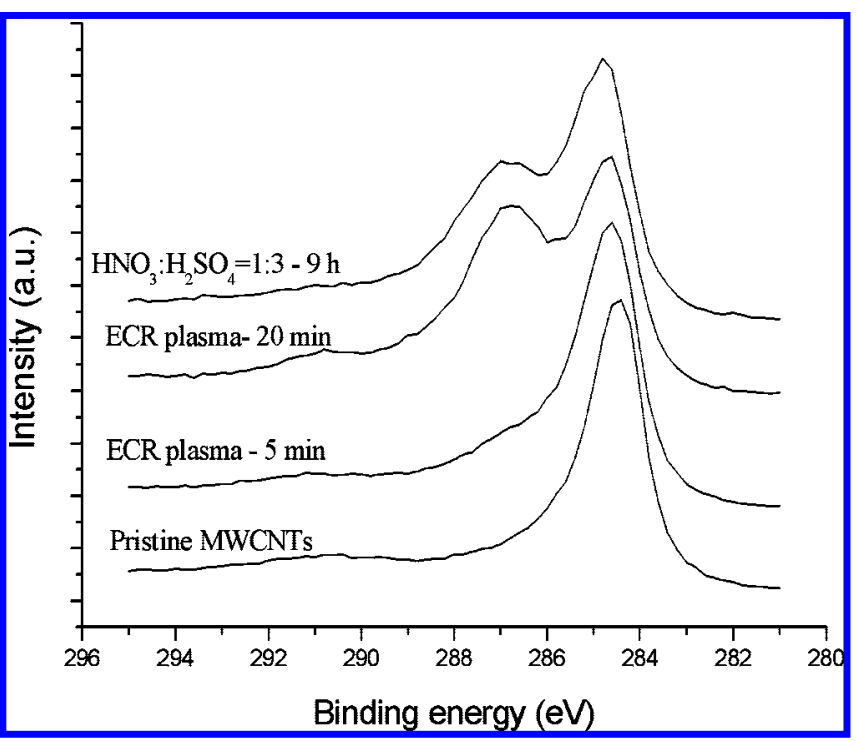

Figure 6. XPS $\mathrm{C} 1 \mathrm{~s}$ spectra of the MWCNTs treated by different treatments.

percentage of amorphous carbon is observed to be reduced. It is obvious that the sample treated by the ECR plasma for 20 min has a higher graphite content $(27.1 \%)$ and less amorphous carbon (13.1\%) than the acid treated sample. The results support that this method is highly effective in introducing oxygen functional groups and simultaneously removing carbon impurities.

In general, functional groups are expected to be covalently bonded to the defect sites on the end and side wall of CNTs. ${ }^{31}$ To better understand the extent of defects in the nanotubes, the Raman spectra of the untreated and treated MWCNT samples are presented with two characteristic peaks, D and G bands. It is known that the intensity of the $\mathrm{D}$ band, in the range $\sim 1300-1400 \mathrm{~cm}^{-1}$, is correlated with structural disorder originating from any defect and amorphous carbon on the walls of MWCNTs, and the G band $\left(\sim 1500-1600 \mathrm{~cm}^{-1}\right)$ is related to the graphite signal. ${ }^{32}$ It is further suggested that the intensity of the D band is defect-activated and the broad line-width of it indicates the high content of carbon impurity, such as amorphous carbon, nanocrystalline graphite, charcoal, and vitreous carbon. ${ }^{32,33}$ Furthermore, the $I_{\mathrm{D}} / I_{\mathrm{G}}$ ratio is a good indicator of the defect density on nanotube walls. ${ }^{33}$

As reported in Figure 7 and Table 1, after the MWCNTs are treated by the ECR plasma for $5 \mathrm{~min}$, the measurement of Raman spectroscopy displays a higher $I_{\mathrm{D}} / I_{\mathrm{G}}$ ratio (1.06) than that of the pristine MWCNTs (0.88). This increase may reflect the fact that the plasma treatment can introduce high density defects on the surface of the nanotubes effectively, even as compared to the acid treatment. It is observed that when the process time of the ECR plasma treatment increases to $20 \mathrm{~min}$, the $I_{\mathrm{D}} / I_{\mathrm{G}}$ ratio value decreases to 1.00 . As suggested by Osswald et al., ${ }^{33}$ this decrease may be due to the removal of the amorphous carbon layer coating on the surface of the MWCNTs. Note that the spectra are normalized with respect to $G$ band intensity.

As shown in Figure 8, the results of TGA show that, with a decomposition temperature of $600{ }^{\circ} \mathrm{C}$, the pristine MWCNT sample is more thermally stable toward oxidative degradation than the MWCNT samples treated by the ECR plasma for 5 and $20 \mathrm{~min}$. However, the difference between the untreated and ECR plasma treated samples is marginal. It is known that the oxidation stability correlates with the combing effect of defects and the diameter of the nanotubes. ${ }^{10}$ With the same diameter 
TABLE 1: The MWCNT Specimen Treated by Different Treatments ${ }^{a}$

\begin{tabular}{|c|c|c|c|c|c|c|c|}
\hline \multirow[b]{2}{*}{ specimen } & \multicolumn{6}{|c|}{ XPS } & \multirow[b]{2}{*}{$\operatorname{Raman}\left(I_{\mathrm{D}} / I_{\mathrm{G}}\right)$} \\
\hline & $\mathrm{sp}^{2}$ graphite $(\%)$ & $\mathrm{sp}^{3}$ contamination $(\%)$ & $\mathrm{C}-\mathrm{O}(\%)$ & $\mathrm{C}=\mathrm{O}(\%)$ & $\mathrm{COO}(\%)$ & {$[\mathrm{O}] /[\mathrm{C}](\%)$} & \\
\hline pristine MWCNTs & 48.8 & 40 & 1 & 8.4 & 1.8 & 11.2 & 0.88 \\
\hline ECR plasma $-20 \mathrm{~min}$ & 27.1 & 13.1 & 24.3 & 32.3 & 3.2 & 59.8 & 1.00 \\
\hline $\mathrm{HNO}_{3}: \mathrm{H}_{2} \mathrm{SO}_{4}=1: 3-9 \mathrm{~h}$ & 22.6 & 24.5 & 15.7 & 28 & 9 & 52.7 & 0.92 \\
\hline
\end{tabular}

${ }^{a}$ The $I_{\mathrm{D}} / I_{\mathrm{G}}$ ratio of Raman spectra; the relative percentage of the five XPS components of carbon atoms; and the ratio of the oxygenated groups to the total number of carbon atoms detected.

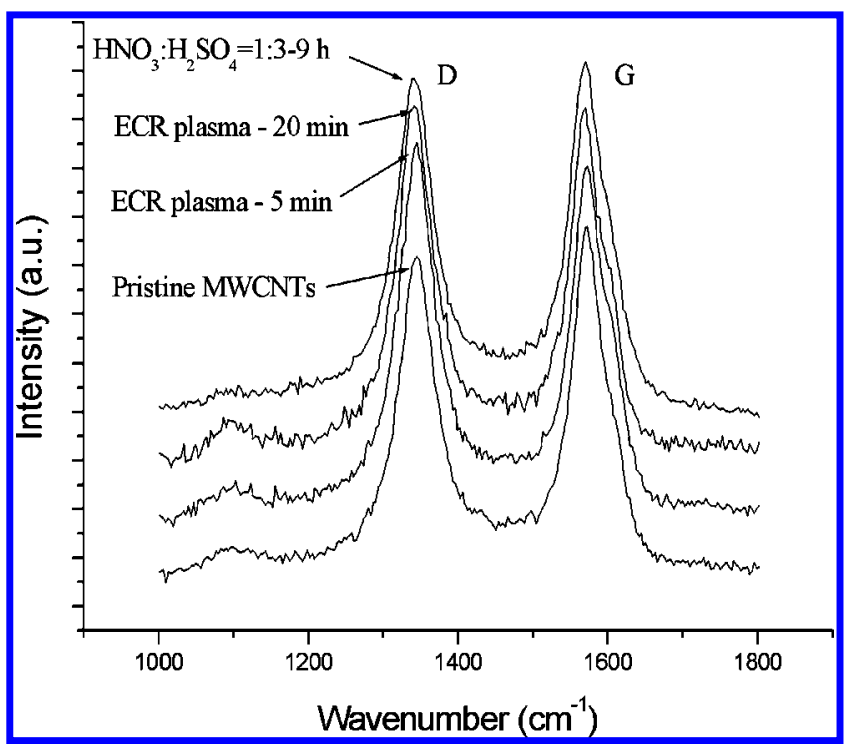

Figure 7. Raman spectra of the MWCNTs treated by different treatments.

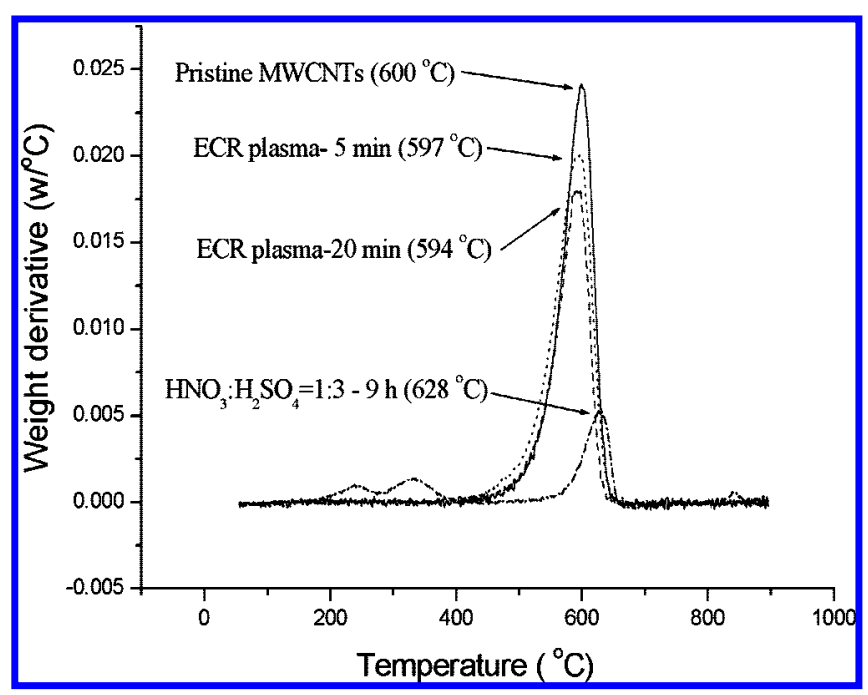

Figure 8. The weight-derivative curves of TGA on the MWCNTs treated by different treatments.

distribution, these results support that the defects can be introduced to the surface of nanotubes by the plasma treatment and the concentration increases with treatment time. Meanwhile, the slight decomposition temperature decrease also depicts that, after the plasma treatment, the nanotubes still have almost the same structural integrity as the pristine sample. This matches the observation results of SEM (Figure $2 \mathrm{a}-\mathrm{c}$ ) and TEM (Figure 3).

On the other hand, after the MWCNTs are treated by $\mathrm{HNO}_{3} /$ $\mathrm{H}_{2} \mathrm{SO}_{4}$ solution for $9 \mathrm{~h}$, the oxidation reaction occurs at $\sim 628$ ${ }^{\circ} \mathrm{C}$. The increase of the oxidization reaction temperature may reflect the fact that there is significant structural change during acid treatment so that the MWCNTs with smaller diameter are oxidized and then destroyed in the harsh environment. Therefore, only nanotubes with large diameters remain but with shorter lengths (cf. Figure 2d), because of their higher stability, which helps to retard defect propagation on the walls of the nanotubes. This also raises the concerns that material loss can be massive and some properties, such as electrical conductivity, can be unavoidably altered..$^{34,35}$ By contrast, based on the various characterization techniques, the ECR plasma treatment can introduce dense defects and functional groups on nanotube surface without causing large structure damage, and the structural integrity and most natural properties of the nanotubes may thus be preserved from the effects of the ion bombardment and oxidization.

It is noted that the presence of the uncertainties in the results of XPS, Raman spectroscopy, and TGA may slightly change the data provided above. Uncertainty analysis based on sufficient experiments data is required to revise the process parameters if the proposed method is to be applied for practical uses. Although the analysis has not been conducted yet, the present results are still reliable enough to characterize the performance of this method qualitatively.

\section{Conclusion}

In conclusion, this study presents an overview of the surface modification of MWCNTs by the ECR plasma. We have found that, as compared to the harsh acid treatment using $\mathrm{HNO}_{3} / \mathrm{H}_{2} \mathrm{SO}_{4}$ solution with a process time of $9 \mathrm{~h}$, the presented ECR plasma treatment can graft higher concentration of oxygenated groups on nanotube surfaces $(\sim 60 \%)$ with very short process time (20 min) and without observable negative effects. This is because, with low working pressure, the divergent magnetic flux, and the application of the high negative DC bias voltage $(-250$ DCV), this method can produce high density and high incident energy hydrogen and oxygen cations to create dense defects on the surface of the nanotubes through ion bombardment. In addition, the high reduction potential oxygen cations are capable of oxidizing the surface of CNTs so that functional groups can form on the side walls effectively. The SEM and TEM characterization results have shown that the proposed method is adequate for our purposes in that the structure and morphology changes of the resulting materials are almost negligible. Most importantly, the results of Raman and TGA reveal that this method tends to create defects allowing functional groups to effectively form on the nanotube surface, while the thermal stability changes between the pristine and the plasma treated samples are marginal.

Acknowledgment. We would like to thank Mr. Yi-Hung Chou for technical support and suggestions.

\section{References and Notes}

(1) Saito, R.; Dresselhous, G.; Dresselhaus, M. S. Physical Properties of Carbon Nanotubes: Imperial College Press: London, 1998. 
(2) Mahar, B.; Laslau, C.; Yip, R.; Sun, Y. IEEE Sens. J. 2007, 7, 266.

(3) Raffaelle, R. P.; Landi, B. J.; Harris, J. D.; Bailey, S. G.; Hepp, A. F. Mater. Sci. Eng., B 2005, 116, 233.

(4) Kim, T.; Kwon, S.; Yoon, H.; Chung, C.; Kim, J. Colloids Surf., A 2008, 313, 448 .

(5) Li, J.; Ng, H. T.; Cassell, A.; Fan, W.; Chen, H.; Ye, Q.; Koehne, J.; Han, J.; Meyyappan, M. Nano Lett. 2003, 3, 597.

(6) Fu, K. F.; Sun, Y. P. J. Nanosci. Nanotechnol. 2003, 3, 351.

(7) Mickelson, E. T.; Huffman, C. B.; Rinzler, A. G.; Smalley, R. E.;

Hauge, R. H.; Margrave, J. L. Chem. Phys. Lett. 1998, 296, 188.

(8) O’Connell, M. J.; Boul, P.; Ericson, L. M.; Huffman, C.; Wang, Y. H.; Haroz, E.; Kuper, C.; Tour, J.; Ausman, K. D.; Smalley, R. E. $\underline{\text { Chem. }}$ Phys. Lett. 2001, 342, 265.

(9) Harutyunyan, A. R.; Pradhan, B. K.; Chang, J. P.; Chen, G. G.; Eklund, P. C. J. Phys. Chem. B 2002, 106, 8671.

(10) Zhang, M.; Yudasaka, M.; Iijima, S. J. Phvs. Chem. B 2004, 108, 149 .

(11) Dumitrescu, L.; Wilson, N. R.; Macpherson, J. V. J. Phvs. Chem. C 2007, 111, 12944 .

(12) Wu, Z. Y.; Xu, Y. Y.; Zhang, X. L.; Shen, G. L.; Yu, R. Q. Talanta 2007, 72, 1336.

(13) Khare, B.; Wilhite, P.; Tran, B.; Teixeira, E.; Fresquez, K.; Mvondo,

D. N.; Bauschlicher, C.; Meyyappan, M. J. Phvs. Chem. B 2005, 109, 23466.

(14) Hassanien, A.; Tokumoto, M.; Umek, P.; Vrbanic, D.; Mozetic, M.; Mihailovic, D.; Venturini, P.; Pejovnik, S. Nanotechnology 2005, 16, 278.

(15) Zheng, G.; Li, Q. Q.; Jiang, K. L.; Zhang, X. B.; Chen, J.; Ren, Z.;

Fan, S. S. Nano Lett. 2007, 7, 1622.

(16) Yu, K.; Zhu, Z. Q.; Zhang, Y. S.; Li, Q.; Wang, W. M.; Luo, L. Q.;

Yu, X. W.; Ma, H. L.; Li, Z. W.; Feng, T. Appl. Surf. Sci. 2004, 225, 380

(17) Zhang, J. H.; Feng, T.; Yu, W. D.; Liu, X. H.; Wang, X.; Li, Q. Diamond Relat. Mater. 2004, 13, 54.

(18) Felten, A.; Bittencourt, C.; Pireaux, J. J.; Van Lier, G.; Charlier,

J. C. J. Appl. Phvs. 2005, 98, 074308-1.

(19) Ionescu, R.; Espinosa, E. H.; Sotter, E.; Llobet, E.; Vilanova, X.; Correig, X.; Felten, A.; Bittencourt, C.; Van Lier, G.; Charlier, J. C.; Pireaux,

J. J. Sens. Actuators, B 2006, 113, 36 .
(20) Juan, C. P.; Tsai, C. C.; Chen, K. H.; Chen, L. C.; Cheng, H. G. C. Jpn. J. Appl. Phys., Part 1 2005, 44, 8231.

(21) Xu, T.; Yang, J. H.; Liu, J. W.; Fu, Q. Appl. Surf. Sci. 2007, 253, 8945.

(22) Khare, B. N.; Wilhite, P.; Quinn, R. C.; Chen, B.; Schingler, R. H.; Tran, B.; Imanaka, H.; So, C. R.; Bauschlicher, C. W.; Meyyappan, M. $\underline{J}$ Phvs. Chem. B 2004, 108, 8166.

(23) Chen, Q. D.; Dai, L. M.; Gao, M.; Huang, S. M.; Mau, A. J.Phvs. Chem. B 2001, 105, 618.

(24) Zhu, Y. W.; Cheong, F. C.; Yu, T.; Xu, X. J.; Lim, C. T.; Thong, J. T. L.; Shen, Z. X.; Ong, C. K.; Liu, Y. J.; Wee, A. T. S.; Sow, C. H. Carbon 2005, 43, 395.

(25) Khare, B. N.; Wilhite, P.; Meyyappan, M. Nanotechnology 2004, 15,1650 .

(26) Ahn, K. S.; Kim, J. S.; Kim, C. O.; Hong, J. P. Carbon 2003, 41, 2481

(27) Seitaro Matsuo; Adachi, Y. Jpn. J. Appl. Phys. 1982, 21, L4.

(28) Ago, H.; Kugler, T.; Cacialli, F.; Salaneck, W. R.; Shaffer, M. S. P.; Windle, A. H.; Friend, R. H. J. Phvs. Chem. B 1999, 103, 8116.

(29) Zhang, Y.; Yuan, S. L.; Zhou, W. W.; Xu, J. J.; Li, Y. J. Nanosci. Nanotechnol. 2007, 7, 2366.

(30) Hofmann, S.; Sharma, R.; Ducati, C.; Du, G.; Mattevi, C.; Cepek, C.; Cantoro, M.; Pisana, S.; Parvez, A.; Cervantes-Sodi, F.; Ferrari, A. C.; Dunin-Borkowski, R.; Lizzit, S.; Petaccia, L.; Goldoni, A.; Robertson, J. Nano Lett. 2007, 7, 602 .

(31) Banerjee, S.; Kahn, M. G. C.; Wong, S. S. Chem.-Eur. J. 2003, 9, 1899 .

(32) Dillon, A. C.; Yudasaka, M.; Dresselhaus, M. S. J. Nanosci. Nanotechnol. 2004, 4, 691.

(33) Osswald, S.; Havel, M.; Gogotsi, Y. J. Raman Spectrosc. 2007, 38,728 .

(34) Kovtyukhova, N. I.; Mallouk, T. E.; Pan, L.; Dickey, E. C. J.Am. Chem. Soc. 2003, 125, 9761.

(35) Zhu, J.; Yudasaka, M.; Zhang, M. F.; Iijima, S. J.Phvs. Chem. B 2004, 108, 11317.

JP8028165 